Article

\title{
Cytotoxic Tirucallane Triterpenoids from Melia azedarach Fruits
}

Nikoletta G. Ntalli ${ }^{1}$, Filippo Cottiglia ${ }^{2}$, Carlos A. Bueno ${ }^{3}$, Laura E. Alché ${ }^{3}$, Marco Leonti ${ }^{2}$, Simona Vargiu ${ }^{4}$, Ersilia Bifulco ${ }^{4}$, Urania Menkissoglu-Spiroudi ${ }^{1}$ and Pierluigi Caboni ${ }^{4, *}$

1 Pesticide Science Laboratory, Faculty of Agriculture, Aristotle University of Thessaloniki, 54124 Thessaloniki, Greece

2 Dipartimento Farmaco Chimico Tecnologico, University of Cagliari, via Ospedale 72, 09124 Cagliari, Italy

3 Bueno, C.A. and Alché, L.E. Laboratorio de Virología, Departamento de Química Biológica, Facultad de Ciencias Exactas y Naturales, Universidad de Buenos Aires, Pabellón 2, 4to. Piso, Ciudad Universitaria, Buenos Aires, Argentina

4 Department of Toxicology, Università degli Studi di Cagliari, via Ospedale 72, 09124 Cagliari, Italy

* Author to whom correspondence should be addressed; E-Mail: caboni@unica.it; Tel.: +390706758617; Fax: +390706758612.

Received: 19 July 2010; in revised form: 18 August 2010 / Accepted: 25 August 2010 /

Published: 27 August 2010

\begin{abstract}
The phytochemical investigation of the dichloromethane-soluble part of the methanol extract obtained from the fruits of Melia azedarach afforded one new tirucallanetype triterpene, 3- $\alpha$-tigloylmelianol (1) and three known tirucallanes, melianone (2), 21- $\beta$ acetoxy-melianone (3), and methyl kulonate (4). The structure of the isolated compounds was mainly determined by 1D and 2D NMR experiments as well as HPLC-Q-TOF mass spectrometry. The cytotoxicity of the isolated compounds toward the human lung adenocarcinoma epithelial cell line A549 was determined, while no activity was observed against the phytonematode Meloidogyne incognita.
\end{abstract}

Keywords: methyl kulonate; 3- $\alpha$-tigloylmelianol; melianone; $21-\beta$-acetoxy-melianone; cytotoxicity 


\section{Introduction}

Melia azedarach L. is a botanical species belonging to the family Meliaceae also known as Ku-lian, China tree or Chinaberry tree. It is native to Asia but is now found in parts of Northern Australia, Africa, North America, tropical South America and Southern Europe. In South America is commonly known as "paraiso" or paradise, and in the US as Indian lilac or white cedar. In Traditional Chinese Medicine, it is used as an antiparasitic and antifungal agent, but many of its constituent compounds have been found to exhibit a wide range of other biological properties [1-12]. The main group of biologically active compounds concentrated in Chinaberry's fruits are called limonoids, consisting of a large group of lipophilic substances [13].

Limonoids are metabolically altered triterpenes and have a prototypical structure either containing or derived from a precursor with a 4,4,8-trimethyl-17-furanylsteroid skeleton. Of the 300 limonoids known today, about one third, also known as meliacins, are obtained from Meliaceae species (Azadirachta indica and Melia azedarach). Limonoids have attracted much attention due to their wide range of properties permitting both pharmacological and plant protection applications [1,2,10,13-15]. Some of the most important biological properties of the limonoids are the antioxidant [12], anticancer [11,16], antimalarial [17], anthelmintic [18], antibacterial [19], antifungal [6,7], and insecticidal effects against disease vectors [4] as well as insect pests $[1,2,14]$. From an ecological standpoint limonoids are not harmful to ecosystems because they are not toxic to parasitoids and predators [20,21] and they have a relatively short residual life [22,23]. Nevertheless, at high concentration levels they can be poisonous to humans [24]. In our previous study we have reported the nematicidal activity of the methanol $(\mathrm{MeOH})$ extract obtained from the ripe fruits of $M$. azedarach against Meloidogyne incognita second stage juveniles (J2) [8]. In the present investigation we report on the chemical characterisation of the tirucallane triterpenoids isolated from the dichloromethane (DCM) soluble fraction of the $\mathrm{MeOH}$ extract, and on their individual activity against nematodes. We also report on the antiproliferative activity and effect of the purified compounds on viability of a lung adenocarcinoma epithelial cell line.

\section{Results and Discussion}

\subsection{Chemistry}

Regarding the biological activities of triterpenoids the investigations need to focus on the optimization of extraction methods, detailed structural characterization, quantification, and structure activity delineation so that they can be safely introduced in our arsenal of pharmaceuticals used against diseases [13]. The phytochemical analysis of the DCM soluble fraction of the $\mathrm{MeOH}$ extract resulted in the identification of one new tirucallane triterpenoid 1 and three known ones 2-4 (Figure 1). The respective $M$. azedarach yields in triterpenoids expressed as dry fruits' weight are presented in Table 1. All the isolated compounds were purified by means of open column chromatography. 
Figure 1. Structures of tirucallane triterpenoids from M. azedarach. 3- $\alpha$-tigloylmelianol (1) and melianone (2), two known protolimonoids were also isolated and identified as 21$\beta$-acetoxymelianone (3) and methyl kulonate (4).
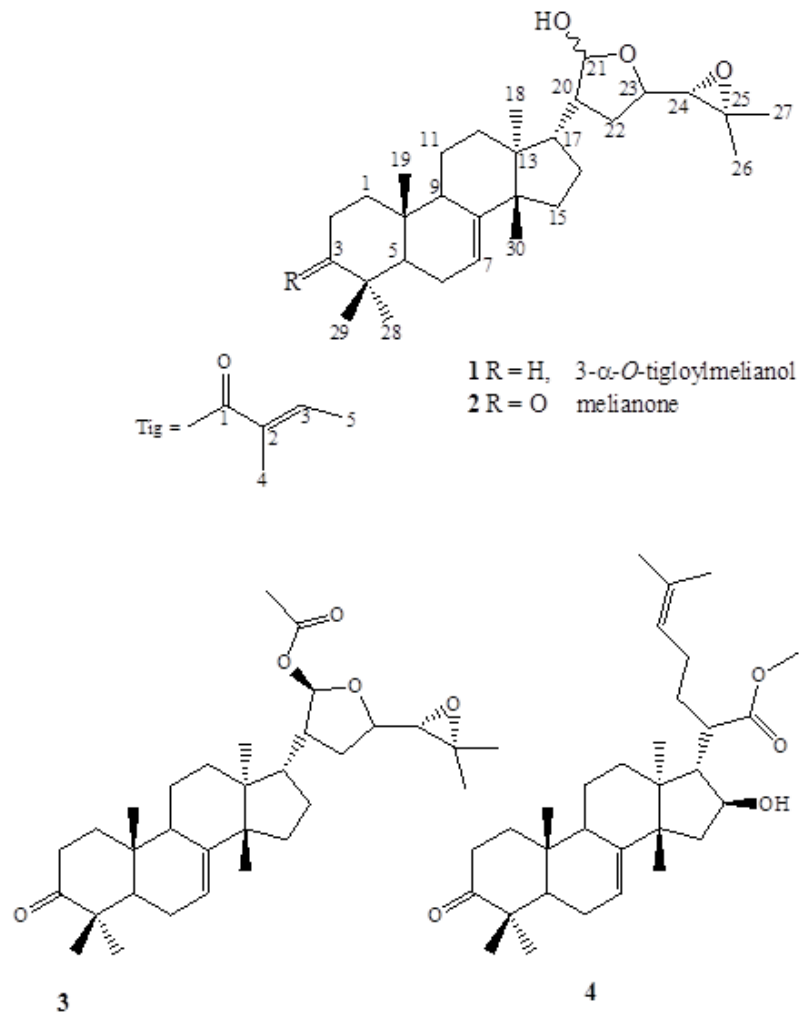

Table 1. Yield of tirucallane triterpenoids from dried fruits of Melia azedarach.

\begin{tabular}{|c|c|}
\hline Compound & $\begin{array}{c}\text { Yield } \\
\mathrm{mg}^{\prime} \mathrm{kg}^{\mathrm{a}}(\mathrm{w} / \mathrm{w})\end{array}$ \\
\hline Melianone & 130 \\
\hline 21- $\beta$-Acetoxymelianone & 16 \\
\hline Methyl kulonate & 35 \\
\hline 3- $\alpha$-Tigloylmelianol & 78 \\
\hline
\end{tabular}

${ }^{a}$ Expressed as dry fruit weight.

Compound 1 was obtained as an amorphous white powder. Its ESI MS displayed a pseudomolecular ion at $m / z 577[\mathrm{M}+\mathrm{Na}]^{+}$, whereas the HR-TOF-ESI MS revealed a pseudomolecular ion at $m / z 555.4093[\mathrm{M}+\mathrm{H}]^{+}$(calc. 555.4044). The data were consistent with the molecular formula $\mathrm{C}_{35} \mathrm{H}_{54} \mathrm{O}_{5}$. The ${ }^{1} \mathrm{H}-\mathrm{NMR}$ spectrum showed ten tertiary $\left(\delta_{\mathrm{H}} 0.76,0.81,0.90,0.95,0.96,0.98,1.27,1.28\right.$, $1.29,1.81)$ and one secondary methyl groups $\left[\delta_{\mathrm{H}} 1.75(\mathrm{~d}, J=6.8 \mathrm{~Hz})\right]$, two olefinic protons $\left[\delta_{\mathrm{H}} 6.80\right.$ (qq, $J=6.8,1.6 \mathrm{~Hz}), 5.24, \mathrm{~m}]$ and seven oxy-methines at $\delta 5.34(\mathrm{~d}, J=2.8 \mathrm{~Hz}), 5.29(\mathrm{~d}, J=2.8 \mathrm{~Hz})$, 4.68 ( $\mathrm{br} \mathrm{s}), 4.10(\mathrm{~m}), 4.15(\mathrm{~m}), 2.82(\mathrm{~d}, J=7.6 \mathrm{~Hz}), 2.67$ (d, $J=7.6 \mathrm{~Hz}$ ) (Table 2). Detailed analyses of ${ }^{1} \mathrm{H}$ - and ${ }^{13} \mathrm{C}-\mathrm{NMR}$ spectra revealed that 1 shared high structural similarity to melianone (2) [25] with the main difference between the two compounds being the presence of an oxy-methine at $\delta_{\mathrm{H}} 4.68\left(\delta_{\mathrm{C}}\right.$ 78.3) at C-3 instead of the ketone group in melianone (2) (Table 2). The ${ }^{13} \mathrm{C}-\mathrm{NMR}$ spectrum of $\mathbf{1}$ (Table 2) exhibited five further signals at $\delta 167.5,136.6,129.2,14.4$ and 12.2, which were sorted by DEPT 135 experiment into two $\mathrm{CH}_{3}(\delta 14.4,12.2 \mathrm{ppm})$, one $\mathrm{CH}(\delta 136.6 \mathrm{ppm})$ and two quaternary 
carbons $(\delta 167.5,129.2)$. The above mentioned carbons could be easily ascribable to a tiglate [26]. In the HMBC spectrum of 1 (Figure 2) the correlation of $\delta_{\mathrm{H}} 0.81(\mathrm{H}-28)$ and $\delta_{\mathrm{H}} 0.95(\mathrm{H}-29)$ with $\delta_{\mathrm{C}} 36.9$ $(\mathrm{C}-4), 46.1(\mathrm{C}-5), 78.3(\mathrm{C}-3)$ and of $\delta_{\mathrm{H}} 4.68(\mathrm{H}-3)$ with $\delta_{\mathrm{C}} 167.5$ (C-1'), $36.9(\mathrm{C}-4), 46.1$ (C-5), 32.1 (C-1), 27.5 (C-2), 27.6 (C-28) and 21.4 (C-29) fixed the tigloyloxy group at the C-3 position of 1 . The broad singlet of $\mathrm{H}-3$ suggested an $\alpha$-orientation of the tigloyloxy moiety. This assignment was supported by correlation of $\delta_{\mathrm{H}} 4.68(\mathrm{H}-3)$ with $\delta_{\mathrm{H}} 076(\mathrm{H}-19)$ in the ROESY spectrum. The HSQC spectra of compounds 1 and 2 showed correlation of the C-21 group resonances at $\delta 97.8$ and 101.8 with H-21 [at $\delta 5.29(\mathrm{~d}, J=2.8 \mathrm{~Hz})$ and $5.33(\mathrm{~d}, J=2.8 \mathrm{~Hz})$ for 1 and at $\delta 5.27(\mathrm{~d}, J=2.7 \mathrm{~Hz})$ and $5.32(\mathrm{~d}, J=2.7 \mathrm{~Hz})$ for 2], characterising them as C-21 epimers. The structure of compound 1 was finally confirmed by extensive 2D NMR measurements as 3- $\alpha$-tigloylmelianol (1).

Figure 2. Key HMBC correlations $(\mathrm{H} \rightarrow \mathrm{C})$ of compound 1.

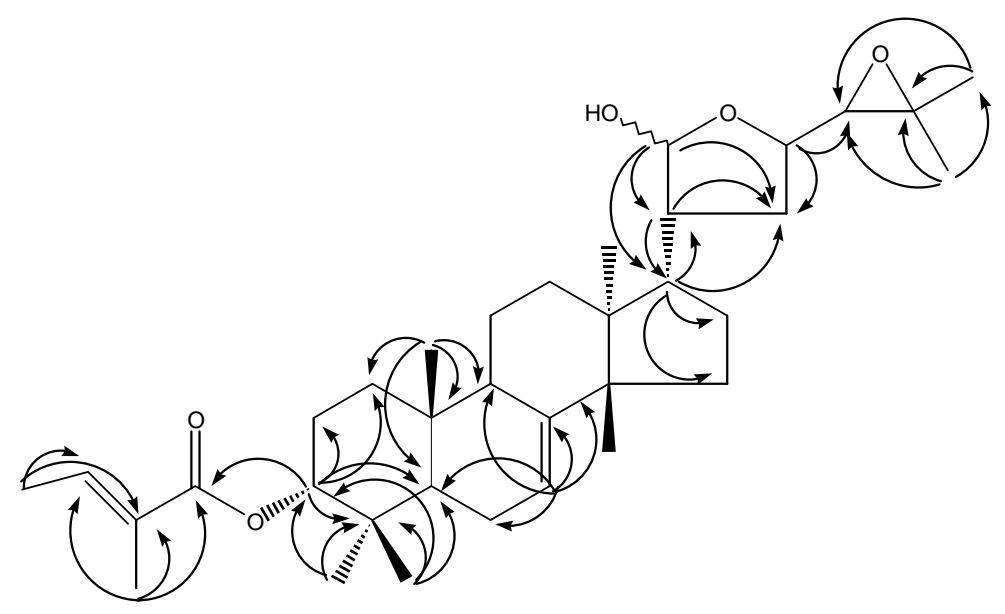

Besides 3- $\alpha$-tigloylmelianol (1) and melianone (2), two known protolimonoids were also isolated and identified as 21- $\beta$-acetoxymelianone (3) and methyl kulonate (4) (Figure 1) [26-29].

Table 2. ${ }^{1} \mathrm{H}$ - and ${ }^{13} \mathrm{C}-\mathrm{NMR}$ data for compounds 1-2 $\left(\mathrm{CDCl}_{3}, \delta\right.$ in ppm and $J$ in $\left.\mathrm{Hz}\right)$.

\begin{tabular}{|c|c|c|c|c|}
\hline \multirow{2}{*}{ Position } & \multicolumn{2}{|l|}{1} & \multicolumn{2}{|l|}{2} \\
\hline & $\delta_{H}$ & $\delta_{\mathrm{C}}$ & $\delta_{H}$ & $\delta_{\mathrm{C}}$ \\
\hline $1 \mathrm{a}$ & $1.39(\mathrm{~m})$ & 32.1 & & 38.5 \\
\hline $1 b$ & $167(\mathrm{~m})$ & & & \\
\hline 2 & $1.49(\mathrm{~m})$ & 27.5 & 2.24 ddd $(14.3,14,6.4)$ & 35.1 \\
\hline & $1.85(\mathrm{~m})$ & & 2.75 ddd $(14.3,3.6,3.4)$ & \\
\hline 3 & $4.68(\mathrm{~s} \mathrm{br})$ & 78.3 & & $216.8 ; 216.7$ \\
\hline 4 & & 36.9 & & 47.9 \\
\hline 5 & $1.79(\mathrm{~m})$ & 46.1 & $1.82(\mathrm{~m})$ & $52.5 ; 52.4$ \\
\hline 6 & $1.73(\mathrm{~m})$ & 22.9 & $1.70(\mathrm{~m})$ & 23.3 \\
\hline 7 & $5.23(\mathrm{~d}, 2.4)$ & $118.2 ; 118.1$ & $5.28 \mathrm{br}$ & $118.2 ; 118.1$ \\
\hline 8 & & $146.0 ; 145.9$ & & $145.8 ; 145.6$ \\
\hline 9 & $2.30(\mathrm{t}, 7.6) ; 2.2(\mathrm{t}, 7.6)$ & $49.7 ; 48.8$ & & $49.6 ; 48.4$ \\
\hline 10 & & 34.9 & & 34.9 \\
\hline 11 & $1.54(\mathrm{~m})$ & 17.4 & & 17.8 \\
\hline $12 \mathrm{a}$ & $1.53(\mathrm{~m})$ & 35.3 & & 35.2 \\
\hline $12 b$ & $1.98(\mathrm{~m})$ & & & \\
\hline 13 & & $43.8 ; 43.6$ & & $43.8 ; 43.6$ \\
\hline
\end{tabular}


Table 2. Cont.

\begin{tabular}{|c|c|c|c|c|}
\hline 4 & & $50.9 ; 50.4$ & & $50.8 ; 50.5$ \\
\hline 15 & $1.55(\mathrm{~m})$ & 34.2 & & 34.3 \\
\hline 16 & $1.61(\mathrm{~m})$ & $27.5 ; 27.1$ & & $27.5 ; 27.3$ \\
\hline 17 & $2.01(\mathrm{~m}) ; 2.04(\mathrm{~m})$ & $47.1 ; 45.2$ & $2.03(\mathrm{~m}) ; 2.06(\mathrm{~m})$ & $47.1 ; 45.2$ \\
\hline 18 & $0.90(\mathrm{~s})$ & 23.9 & $0.80(\mathrm{~s}) ; 085(\mathrm{~s})$ & 24.6 \\
\hline 19 & $0.76(\mathrm{~s})$ & 13.0 & & 12.8 \\
\hline 20 & $1.71(\mathrm{~m})$ & $33.8 ; 31.7$ & & $33.8 ; 31.7$ \\
\hline 21 & $5.33(\mathrm{~d}, 2.8) ; 5.29(\mathrm{~d}, 2.8)$ & $101.8 ; 97.8$ & & $101.8 ; 97.8$ \\
\hline 22 & $1.98(\mathrm{~m})$ & $31.5 ; 31.3$ & & $31.5 ; 31.3$ \\
\hline 23 & $3.89(\mathrm{~m}) ; 3.83(\mathrm{~m})$ & $78.5 ; 77.0$ & $3.88(\mathrm{~m}) ; 3.84(\mathrm{~m})$ & $78.5 ; 77.1$ \\
\hline 24 & $2.82(\mathrm{~d}, 7.6) ; 2.67(\mathrm{~d}, 7.6)$ & $67.8 ; 65.3$ & $2.81(\mathrm{~d}, 7.6) ; 2.67(\mathrm{~d}, 7.6)$ & $67.8 ; 65.4$ \\
\hline 25 & & $58.0 ; 57.2$ & & $58.0 ; 57.2$ \\
\hline $26^{\text {a) }}$ & $1.29(\mathrm{~s}) ; 1.28(\mathrm{~s})$ & $25.0 ; 24.9$ & $1.29(\mathrm{~s}) ; 1.28(\mathrm{~s})$ & $25.0 ; 24.9$ \\
\hline $27^{\text {a) }}$ & $1.27(\mathrm{~s})$ & $19.4 ; 19.2$ & $1.26(\mathrm{~s})$ & $19.5 ; 19.2$ \\
\hline 28 & $0.81(\mathrm{~s})$ & 27.6 & $0.97(\mathrm{~s})$ & 24.4 \\
\hline 29 & $0.95(\mathrm{~s})$ & 21.4 & $0.98(\mathrm{~s})$ & 21.6 \\
\hline 30 & $0.98(\mathrm{~s}) ; 0.96(\mathrm{~s})$ & $22.6 ; 22.3$ & $1.00(\mathrm{~s}) ; 1.07(\mathrm{~s})$ & 22.6 \\
\hline $1^{\prime}$ & & 167.5 & & \\
\hline $2^{\prime}$ & & 129.2 & & \\
\hline $3^{\prime}$ & $6.80(\mathrm{qq}, 6.8,1.6)$ & 136.6 & & \\
\hline $4^{\prime}$ & $1.75(\mathrm{~d}, 6.8)$ & 14.4 & & \\
\hline $5^{\prime}$ & $1.81(\mathrm{~s})$ & 12.2 & & \\
\hline
\end{tabular}

\subsection{Cytotoxic and antiproliferative activities}

The literature concerning the cytotoxic properties of limonoids is extensive [10,13,16,30-33] and recent efforts are designed to investigate the cellular and molecular mechanisms by which such effects are exerted in the tumorigenic cell lines [34]. Nevertheless, the biological activity of the limonoids isolated and identified in this study is limited. Melianone possesses cytotoxic properties [29], acts against Trypanosoma cruzi (Protista) [35] and activates hepatic metabolic enzymes in rat [36]. Methyl kulonate is reported to have anticancer properties [33]. Herein, the human lung adenocarcinoma epithelial cell line A549 was chosen to determine the cytotoxic and antiproliferative activities of 21- $\beta$ acetoxymelianone, methyl kulonate, 3 - $\alpha$-tigloylmelianol and melianone. Human lung adenocarcinoma A549 cells were grown in MEM 10\%. Cell cultures were maintained in a $4 \% \mathrm{CO}_{2}$ humidified atmosphere at $37{ }^{\circ} \mathrm{C}$. When the cytotoxic activity was assayed, the percentage of surviving cells decreased gradually with the increase in the concentration of $21-\beta$-acetoxymelianone, 3 - $\alpha$-tigloylmelianol, and melianone after 24-hour incubation, whereas methyl kulonate showed no cytotoxicity at any of the concentrations tested (data not shown). The $\mathrm{CC}_{50}$ values of $21-\beta$-acetoxymelianone, $3-\alpha$ tigloylmelianol and melianone were $90.6,64.7$ and $3.6 \mu \mathrm{g} / \mathrm{mL}$, respectively, indicating that melianone exhibited the highest cytotoxic effect. Only $21-\beta$-acetoxymelianone and 3 - $\alpha$-tigloylmelianol showed moderate antiproliferative effect, with $\mathrm{IC}_{50}$ values of 100 and $91.8 \mu \mathrm{g} / \mathrm{mL}$. These results demonstrate that 21- $\beta$-acetoxymelianone and 3- $\alpha$-tigloylmelianol gather both, cytotoxic and antiproliferative activities, although 3- $\alpha$-tigloylmelianol proved to be more cytotoxic than $21-\beta$-acetoxymelianone. Finally, neither cytotoxic nor antiproliferative activity was found for methyl kulonate (data not shown) and 3- $\alpha$-tigloylmelianol exhibited no cytotoxic effect in a normal Vero cell line, derived from kidney epithelial cells of the African Green Monkey (Barquero A., personal communication). The antiproliferative and cytotoxic activity of 3- $\alpha$-tigloylmelianol and melianone are presented in Figure 3. 
Figure 3. Regression curves of cytotoxic and antiproliferative activity of 3- $\alpha$ tigloylmelianol and melianone against the tumorigenic cell line A549.
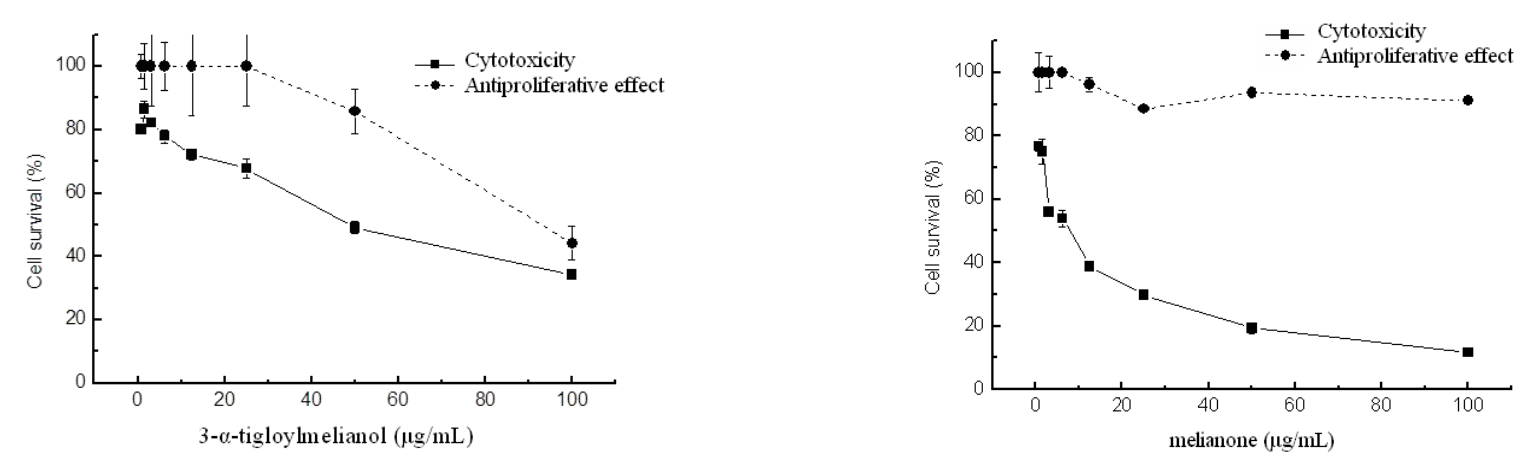

\subsection{Nematicidal activity}

The isolated triterpenoids as well as limonin were evaluated for their nematicidal activity against $M$. incognita. All compounds had no significant effect on $\mathrm{J} 2$ motility after $4 \mathrm{~d}$ of immersion in solutions at the dose range of 31.2-500 $\mu \mathrm{g} / \mathrm{mL}$ (data not shown). These results are in accordance with our previous findings, where the limonoid azadirachtin was not found to possess nematicidal activity against $M$. incognita [37], and agree with the conclusion that M. azedarach nematicidal activity is not related to its limonoids contents.

\section{Experimental}

\subsection{General}

UV spectra were recorded on a GBC Cintra 5 spectrophotometer. Melting points were determined on a Köfler apparatus and are uncorrected. NMR spectra were recorded at $25^{\circ} \mathrm{C}$ on a Varian UNITY INOVA $400 \mathrm{MHz}$, operating at $400 \mathrm{MHz}$ for ${ }^{1} \mathrm{H}$ and $100 \mathrm{MHz}$ for ${ }^{13} \mathrm{C}$, respectively. Compounds were measured in $\mathrm{CDCl}_{3}$ and the spectra referenced against residual non-deuterated solvents. LC-MS DAD analysis: low resolution MS was performed on a Varian tandem mass spectrometer (Paolo Alto, CA) consisting of a ProStar 410 autosampler, two ProStar 210 pumps, and a $1200 \mathrm{~L}$ triple quadrupole mass spectrometer. The column used was a Phenomenex GEMINI $3 \mu \mathrm{m} \mathrm{C}_{18} 110 \mathrm{~A}(100 \times 4.6 \mathrm{~mm})$. The mobile phase consisted of (A) $0.1 \%$ formic acid in water and (B) methanol. The solvent gradient started at $20 \% \mathrm{~A}$ and $80 \% \mathrm{~B}$, reaching $100 \% \mathrm{~B}$ at $10 \mathrm{~min}$, and it was held in these conditions up to $30 \mathrm{~min}$. For the following $5 \mathrm{~min}$ the mobile phase was re-stabilized at $80 \% \mathrm{~B}$ and it remained at these conditions for $5 \mathrm{~min}$ before every successive injection. The mobile phase was pumped constantly at $0.4 \mathrm{~mL} / \mathrm{min}$ and the injection volume was $20 \mu \mathrm{L}$. The substances revelation was achieved at a spectrum scan from 200 to $600 \mathrm{~nm}$. The software used for the detector's analysis parameters set and for the HPLC data analysis was ChromQuest Version 4.0 Build 1120 and HP Chem, Version A.07.01 respectively. LC-MS analysis was conducted in electrospray ionization interface and the conditions, operated in the positive ion mode, were as follows: capillary potential, $55 \mathrm{~V}$; shield potential, $775 \mathrm{~V}$; needle voltage, $5700 \mathrm{~V}$; nitrogen pressure, 54mTorr; housing temperature, $56{ }^{\circ} \mathrm{C}$; drying gas temperature, $380{ }^{\circ} \mathrm{C}$; scan time 1; detector multiplier voltage, $1200 \mathrm{~V}$; isolation width of $\mathrm{m} / \mathrm{z} 1.6$ for the quadrupole 1; scan 100-1500 amu. HPLC-MS-Q-TOF Analysis: The isolated compounds were 
analyzed by reverse-phase HPLC on an Agilent 1200 series HPLC system fitted with a microchip technology using an Agilent Zorbax 300 SB-C18 $5 \mu \mathrm{m}, 43 \mathrm{~mm} \times 75 \mu \mathrm{m}$ (Agilent, Santa Clara, CA). The HPLC conditions were as follows: flow rate: $0.4 \mu \mathrm{L} / \mathrm{min}$; solvent A: $0.1 \%$ formic acid in water; solvent B: acetonitrile; and gradient: solvent B 5-100\% over $10 \mathrm{~min}$. The samples $(1 \mu \mathrm{L})$ were analyzed by ESI in positive mode using an Agilent 6520 Time of Flight (TOF) MS. Mass spectral data was acquired in the range, $\mathrm{m} / \mathrm{z} 100-1500$ with an acquisition rate of $1.35 \mathrm{spectra} / \mathrm{s}$, averaging 10,000 transients. The source parameters were adjusted as follows: drying gas temperature $250{ }^{\circ} \mathrm{C}$, drying gas flow rate $5 \mathrm{~L} / \mathrm{min}$, nebulizer pressure $45 \mathrm{psi}$, and fragmentor voltage $150 \mathrm{~V}$. Methanol was of high performance liquid chromatography (HPLC) grade (Baker, Milan, Italy); hexane, ethyl acetate, dichloromethane and ethanol were of gas chromatography grade purchased from Baker (Milan, Italy); The aluminium TLC plates $20 \times 20 \mathrm{~cm}$ silica gel $60 \mathrm{~F} 254,0.25 \mathrm{~mm}$ were purchased from Merck, while the silica gel grade 70-230 mesh, $60 \AA$ was purchased from Sigma Chemical Co., Inc. Formic acid used as mobile phase additive in LC-MS analysis was obtained from Fluka/Sigma-aldrich (Italy).

\subsection{Plant material}

Ripe fruits of M. azedarach were collected in Thessaloniki, Greece in February 2007. A voucher specimen was deposited at the Department of Ecology, School of Biology, Aristotle Univeristy of Thessaloniki, Greece for species identification by the Prof. D. Vokou.

\subsection{Extraction and isolation}

The ripe lyophilized powdered fruits of $M$. azedarach $(550 \mathrm{~g})$ were extracted with $n$-hexane $(16.5 \mathrm{~L})$ in a Soxhlet apparatus to remove fatty acids $(19.9 \mathrm{~g})$. The solid residue was extracted with $\mathrm{MeOH}$ to give, after concentration, $200 \mathrm{~g}$ of dry extract. Then, the $\mathrm{MeOH}$ extract was suspended to methanol-water $(50: 50 \mathrm{v} / \mathrm{v})$ and partitioned with DCM to afford a DCM soluble fraction. After concentration, the resulting extract (20 g) was subjected to open column chromatography (CC) (silica gel, 2,100 g) using a step gradient polarity elution. Twenty six L of mixtures of various solvents $(2 \mathrm{~L}$ each eluent) of increasing polarity [ $n$-hexane, DCM, ethyl acetate (EtOAc), and $\mathrm{MeOH}$, beginning from a $100 \% n$-hexane and reaching $100 \% \mathrm{MeOH}$, were used for the column's gradient elution to afford sixty five fractions of $400 \mathrm{~mL}$ each. Fractions $1 \mathrm{~A}-1 \mathrm{E}, n$-hexane eluate; fractions $2 \mathrm{~A}-2 \mathrm{E}, n$ hexane-DCM (75:25) eluate; fractions 3A-3E, $n$-hexane-DCM (50:50) eluate; fractions 4A-4E, $n$ hexane-DCM (25:75) eluate; fractions 5A-5E, DCM eluate; fractions 6A-6E, DCM: EtOAc (75:25) eluate; fractions 7A-7E, DCM-EtOAc (50:50) eluate; fractions 8A-8E, DCM-EtOAc (25:75) eluate; fractions 9A-9E EtOAc eluate; fractions 10A-10E, EtOAc-MeOH (75:25) eluate; fractions 11A-11E, EtOAc-MeOH (50:50) eluate; fractions 12A-12E, EtAOc-MeOH (25:75); fractions 13A-13E, methanol eluate. The collected fractions were evaporated under vacuum and examined by TLC. Homogeneous fractions were pooled to give three major fractions (F1-F3). F1 (506 mg) was subjected to CC (silica gel, $50 \mathrm{~g}$ ) with $620 \mathrm{~mL}$ of $n$-hexane-EtOAc $(70: 30 \mathrm{v} / \mathrm{v})$ to afford $155 \mathrm{subfractions}(\mathrm{F} 1.1$ $\mathrm{F} 1.155)$ of $4 \mathrm{~mL}$ each. The homogeneous subfractions F1.38-F1.43 were combined (52.25 mg) and subjected to CC (silica gel, $6 \mathrm{~g}$ ) with $50 \mathrm{~mL} n$-hexane-EtOAc $(70: 30 \mathrm{v} / \mathrm{v})$ to afford 50 fractions of $1 \mathrm{~mL}$ each. The fractions 13-17 were combined and evaporated, yielding compound 4 (19.5 mg). The homogeneous subfractions F1.56-F1.63 were combined (28.07 mg) and successively purified on CC 
(silica gel, $6 \mathrm{~g})$ with $50 \mathrm{~mL} n$-hexane-EtOAc $(70: 30 \mathrm{v} / \mathrm{v})$ to afford 50 fractions of $1 \mathrm{~mL}$ each. The fractions 11-13 were combined and evaporated to yield compound 3 (8.8 mg). F2 (907 mg) was rechromatographed on CC (silica gel, $90 \mathrm{~g}$ ) with $3.7 \mathrm{~L}$ of $n$-hexane-EtOAc $(70: 30 \mathrm{v} / \mathrm{v}$ ) to afford 188 subfractions (F2.1-F2.188) of $20 \mathrm{~mL}$ of each. The homogeneous subfractions F2.40-F2.42 were combined, evaporated and the yielding $90.09 \mathrm{mg}$ were rechromatographed on CC (silica gel, $9 \mathrm{~g}$ ) with $50 \mathrm{~mL}$ hexane-EtOAc $(80: 20 \mathrm{v} / \mathrm{v})$ to afford 50 fractions of $1 \mathrm{~mL}$ each. Fractions 15-24 were combined and evaporated, yielding compound 1 (42.9 mg). F3 (975 mg) was rechromatographed on CC (silica gel, $95 \mathrm{~g})$ with $3.8 \mathrm{~L}$ of hexane-EtOAc $(70: 30 \mathrm{v} / \mathrm{v})$ to afford 188 subfractions (F3.1-F3.188) of $20 \mathrm{~mL}$ each. The subfractions F3.81-F3.87 were combined and evaporated, yielding $108 \mathrm{mg}$ that were rechromatographed on CC (silica gel, $10 \mathrm{~g}$ ) with $100 \mathrm{~mL}$ of DCM-EtOAc (90:10 v/v) to afford 100 fractions of $1 \mathrm{~mL}$ each. The fractions 45-75 were combined and evaporated yielding compound 2 (71.5 mg).

\subsection{Spectroscopic data}

3- $\alpha$-Tigloylmelianol (1). white amorphous powder; m.p. $194-195 \quad{ }^{\circ} \mathrm{C} ; \quad \mathrm{UV} \quad(\mathrm{MeOH})$ : $\lambda_{\max } \mathrm{nm}(\log \varepsilon)=209.9(3.45)$; HR-ESI MS $(m / z) 555.4093[\mathrm{M}+\mathrm{H}]^{+}($calcd. 555.4044$)$; ESI MS $m / z$ (rel. int.): 552 (12) $[\mathrm{M}]^{+}, 537(90)\left[\mathrm{M}-\mathrm{H}_{2} \mathrm{O}+\mathrm{H}\right]^{+}, 577(84)[\mathrm{M}+\mathrm{Na}]^{+}, 1131(100)[2 \mathrm{M}+\mathrm{Na}]^{+} ;{ }^{1} \mathrm{H}-$ and ${ }^{13} \mathrm{C}-\mathrm{NMR}$ data, see Table 2.

\subsection{Test for in vitro cytotoxic activity}

Cell viability was determined as previously reported [38]. Briefly, cell viability in the presence of the triterpenoids was determined using the cleavage of the tetrazolium salt MTT (3-(4,5-dimethylthiazol-2-yl)-2,5-diphenyltetrazolium bromide) by the mitochondrial enzyme succinate dehydrogenase to give a blue product (formazan). The absorbance of each well was measured on an Eurogenetics MPR-A 4i microplate reader using a test wavelength of $570 \mathrm{~nm}$ and a reference wavelength of $630 \mathrm{~nm}$, by duplicate. Results were expressed as a percentage of absorbance of treated cells with respect to untreated ones. The $\mathrm{CC}_{50}$ was defined as the concentration of compound that caused a $50 \%$ reduction in cell viability.

\subsection{Test for in vitro antiproliferative activity}

$2.4 \times 10^{6}$ cells were seeded in 96-well plates together with different concentrations of the triterpenoids in duplicate, and incubated at $37^{\circ} \mathrm{C}$ for $24 \mathrm{~h}$ in $4 \% \mathrm{CO}_{2}$ atmosphere. Cells were then fixed with $10 \%$ formaldehyde for $15 \mathrm{~min}$ at room temperature, washed once with distilled water and stained with $0.05 \%$ crystal violet in $10 \%$ ethanol for $30 \mathrm{~min}$. Afterwards cells were washed once, and eluted with a solution of $50 \%$ ethanol and $0.1 \%$ acetic acid in water. The absorbance of each well was measured on an Eurogenetics MPR-A 4i microplate reader using a test wavelength of $590 \mathrm{~nm}$. The $\mathrm{IC}_{50}$ was defined as the concentration of compound that caused a $50 \%$ reduction in cell survival. 


\subsection{Second stage juveniles (J2) paralysis bioassays}

Freshly hatched $M$. incognita J2 $(24 \mathrm{~h})$ were extracted from infested tomato roots according to Hussey and Barker (1973) [39] to be used for the experiments. Melianone, 3- $\alpha$-tigloylmelianol, 21- $\beta$ acetoxymelianone and methyl kulonate, were individually subjected to dose response experiments against $\mathrm{J} 2$ at the dose range of $31.2-500 \mu \mathrm{g} / \mathrm{mL}$. In the frame of our research testing limonoids for nematicidal activity, limonin was also subjected in a dose response experiment. Stock solutions were prepared in dimethyl sulfoxide (DMSO) and further dilutions were made in distilled water. Final concentration of DMSO never exceeded $1 \% \mathrm{v} / \mathrm{v}$. The bioassays were carried out in Cellstar ${ }^{\circledR}$ 96-well cell culture plates (Greiner bio-one) and each treatment was represented by $25 \mathrm{~J} 2$ per well. Plates were covered with plastic lids and were maintained in dark at $28^{\circ} \mathrm{C}$. Juveniles were observed with the aid of an inverted microscope (Euromex, Holland) at $40 \times$ and were ranked into two distinct categories: motile or paralyzed. The paralysis experiments were performed twice, and every treatment was replicated per experiment six times. Assessments were made 1day (1d) and 4d after bioassay's start.

\subsection{Statistical analysis}

Since paralysis in solvent (DMSO) was not significantly different from that observed in distilled water, the percentages of paralyzed $\mathrm{J} 2$ recorded in the microwell assays were corrected by eliminating the natural death/paralysis in the water control according to the Schneider Orelli's formula (Puntener, 1981) [40]: Corrected $\%=\{$ (Mortality $\%$ in treatment-Mortality $\%$ in control $) /(100-$ Mortality $\%$ in control) $\} \times 100$ and they were analyzed (ANOVA) after being combined over time. Since ANOVA indicated no significant treatment by time interaction, means were averaged over experiments. Treatment means were compared by Duncan's multiple range tests.

\section{Conclusions}

A new tirucallane triterpenoid, 3- $\alpha$-tigloylmelianol (1), was isolated along with three known tirucallanes (2-4) [25-29] from the dichrolomethane-soluble part of the methanol extract obtained from the fruits of Melia azedarach. 21- $\beta$-acetoxy-melianone (3), 3- $\alpha$-tigoylmelianol (1) and melianone (2) were cytotoxic while 21- $\beta$-acetoxymelianone (3), and 3- $\alpha$-tigloylmelianol (1) showed an additional moderate antiproliferative effect against the human lung adenocarcinoma epithelial cell line A549, suggesting $M$. azedarach potential for further investigation as a natural source of anticancer agents. Similarly to azadirachtin [37], neither the Chinaberry limonoids nor limonin were found to paralyse $M$. incognita juveniles which fact implies that such activity [8] lies elsewhere in the methanol $(\mathrm{MeOH})$ extract obtained from the ripe fruits of M. azedarach.

\section{Acknowledgements}

This study was supported by a grant from the Italian Ministero dell'Istruzione, dell'Università e della Ricerca: Research Program PRIN 2008 "Discovery and evaluation of new microbial and vegetable biopesticides for the natural insect pests control". The project was part of a $\mathrm{PhD}$ thesis funded by the Greek State Scholarships Foundation of Greece. Special thanks to M. Trevisan, and F. Ferrari and G. Sarais for helpful suggestions. 


\section{References}

1. Isman, M.B. Botanical insecticides, deterrents, and repellents in modern agriculture and an increasingly regulated world. Annu. Rev. Entomol. 2006, 51, 45-66.

2. Akhtar, Y.; Yeoung, Y.R.; Isman, M.B. Comparative bioactivity of selected extracts from Meliaceae and some commercial botanical insecticides against two noctuid caterpillars, Trichoplusia ni and Pseudaletia unipuncta. Phytochem. Rev. 2008, 7, 77-88.

3. Carpinella, C.; Ferrayoli, C.; Valladares, G.; Defago, M.; Palacios, S. Potent limonoid insect antifeedant from Melia azedarach. Biosci. Biotechnol. Biochem. 2002, 66, 1731-1736.

4. Coria, C.; Almiron, W.; Valladares, G.; Carpinella, C.; Ludueña, F.; Defago, M.; Palacios. S. Larvicide and oviposition deterrent effects of fruit and leaf extracts from Melia azedarach L. on Aedes aegypti (L.) (Diptera: Culicidae). Bioresource Technol. 2008, 99, 3066-3070.

5. Kamaraj, C.; Rahuman, A.A.; Bagavan, A.; Mohamed, M.J.; Elango, G.; Rajakumar, G.; Zahir, A.A.; Santhoshkumar, T.; Marimuthu, S. Unit Ovicidal and larvicidal activity of crude extracts of Melia azedarach against Haemonchus contortus (Strongylida). Parasitol. Res. 2010, 106, 1071-1077.

6. Carpinella, M.C.; Giorda, L.M.; Ferrayoli, C.G.; Palacios, S.M. Antifungal effects of different organic extracts from Melia azedarach L. on phytopathogenic fungi and their isolated active components. J. Agric. Food Chem. 2003, 51, 2506-2511.

7. Carpinella, M.C.; Ferrayoli, C.G.; Palacios, S.M. Antifungal synergistic effect of scopoletin, a hydroxycoumarin isolated from Melia azedarach L. fruits. J. Agric. Food Chem. 2005, 53, 2922-2927.

8. Ntalli, N.G.; Menkisoglu-Spiroudi, U.; Giannakou, I. Nematicidal activity of powder and extracts of Melia azedarach fruits against Meloidogyne incognita. Ann. Appl. Biol. 2010, 156, 309-317.

9. Vishnukanta, A.C.R. Melia azedarach: A phytopharmacological review. Pharmacogn. Rev. 2008, 2, 173-179.

10. Bueno, C.A.; Alché, L.A.; Barquero, A.A. 1-Cinnamoyl-3,11-dihydroxymeliacarpinin delays glycoprotein transport restraining virus multiplication without cytotoxicity. Biochem. Biophys. Res. Commun. 2010, 393, 32-37.

11. Wu, S.B.; Ji, Y.P.; Zhu, J.J.; Zhao, Y.; Xia, G.; Hu, Y.H.; Hu, J.F. Steroids from the leaves of Chinese Melia azedarach and their cytotoxic effects on human cancer cell lines. Steroids 2009, 74, 761-765.

12. Mazumder, M.E.H.; Rahman, S. Pharmacological evaluation of Bangladeshi medicinal plants for antioxidant activity. Pharm. Biol. 2008, 46, 704-709.

13. Roy, A.; Saraf, S. Limonoids: Overview of significant bioactive triterpenes distributed in plants kingdom. Biol. Pharm. Bull. 2006, 29, 191-201.

14. Morgan, E.D. Azadirachtin, a scientific gold mine. Bioorg. Med. Chem. 2009, 17, 4096-4105.

15. Patil, B.S.; Jayaprakasha, G.K.; Murthy, K.N.C.; Vikram, A. Bioactive compounds: Historical perspectives, opportunities, and challenges. J. Agric. Food Chem. 2009, 57, 8142-8160.

16. Zhang, B.; Wang, Z.F.; Tang, M.Z.; Shi, Y.L. Growth inhibition and apoptosis-induced effect on human cancer cells of toosendanin, a triterpenoid derivative from Chinese traditional medicine. Invest. New Drug. 2005, 23, 547-553. 
17. Muregi, F.W.; Chhabra, S.C.; Njagi, E.N.M.; Lang'at-Thoruwa, C.C.; Njue, W.M.; Orago, A.S.S.; Omar, S.A.; Ndiege, I.O. Anti-plasmodial activity of some Kenyan medicinal plant extracts singly and in combination with chloroquine. Phytother. Res. 2004, 18, 379-384.

18. Madibela, O.R.; Kelemogile, K.M. Exposure of Melia azedarach fruits to Eimeria lowers oocyst output in yearling Tswana goats. Small Ruminant Res. 2008, 76, 207-210.

19. Khanavi, M.; Safavi, M.; Siavoshi, F.; Fallah Tafti, A.; Haji Mahmoodi, M.; Haji Akhoondi, A.; Rezazadeh Sh, R.; Foroumadi, A. Evaluation of anti Helicobacter pylori activity of methanol extracts of some species of Stachys and Melia. J. Med. Plants 2008, 7, 74-80.

20. Peveling, R.; Ely, S.O. Side-effects of botanical insecticides derived from Meliaceae on coccinellid predators of the date palm scale. Crop Prot. 2006, 25, 1253-1258.

21. Matter, M.M.; Gesraha, M.A.; Ahmed, A.A.I.; Farag, N.A. Impact of neem and chinaberry fruit extracts on the pest/parasitoid (Pieris rapae/Hyposoter ebeninus) interactions. Anzeiger für Schädlingskunde 2002, 75, 13-18.

22. Caboni, P.; Sarais, G.; Angioni, A.; Garcia, A.J.; Lai, F.; Dedola, F.; Cabras, P. Residues and persistence of neem formulations on strawberry after field treatment. J. Agric. Food Chem. 2006, 54, 10026-10032.

23. Sarais, G.; Angioni, A.; Lai, F.; Cabras, P.; Caboni, P. Persistence of two neem formulations on peach leaves and fruit: effect of the distribution. J. Agric. Food Chem. 2009, 57, 2457-2461.

24. Phua, D.H.; Tsai, W.J.; Ger, J.; Deng, J.F.; Yang, C.C. Human Melia azedarach poisoning. Clin. Toxicol. 2008, 46, 1067-1070.

25. Nakanishi, T.; Inada, A.; Lavie, D. A new tirucallane-type triterpenoid derivative, lipomelianol from fruits of Melia toosendan SIEB. Et ZUCC. Chem. Pharm. Bull. 1986, 34, 100-104.

26. Joseph-Nathan, P.; Wesener, J.R.; Günther, H. A two-dimensional NMR study of angelic and tiglic acid. Magn. Res. Chem. 1984, 23, 190-191.

27. Su, R.; Kim, M.; Kawaguchi, H.; Yamamoto, T.; Goto, K.; Taga, T.; Miwa, Y.; Kozuka, M.; Takahashi, S. triterpenoids from the fruits of Phellodendron chinense SCHNEID.: the stereostructure of niloticin. Chem. Pharm. Bull. 1990, 38, 1616-1619.

28. Chiang, C.; Chang, F.C. Tetracyclic triterpenoids from Melia azedarach, L.-III. Tetrahedron 1973, 29, 1911-1929.

29. Itokawa, H.; Kishi, E.; Morita, H.; Takeya, K. Cytotoxic quassinoids and tirucallane-type triterpenes from woods of Eurycoma longifolia. Chem Pharm. Bull. 1992, 40, 1053-1055.

30. Zhou, H.; Hamazaki, A.; Fontana, J.D.; Takahashi, H.; Wandscheer, C.B.; Fukuyama, Y. Cytotoxic limonoids from Brazilian Melia azedarach. Chem. Pharm. Bull. 2005, 53, 1362-1365.

31. Zhou, H.; Hamazaki, A.; Fontana, J.D.; Takahashi, H.; Esumi, T.; Wandscheer, C.B.; Tsujimoto, H.; Fukuyama, Y. New ring C-seco limonoids from Brazilian Melia azedarach and their cytotoxic activity. J. Nat. Prod. 2004, 67, 1544-1547.

32. Tada, K.; Takido, M.; Kitanaka, S. Limonoids from fruit of Melia toosendan and their cytotoxic activity. Phytochemistry 1999, 51, 787-791.

33. Pettit, G.R.; Numata, A.; Iwamoto, C.; Morito, H.; Yamada, T.; Goswami, A.; Clewlow, P.J.; Cragg, G.M.; Schmidt, J.M. Antineoplastic agents. 489. Isolation and structures of meliastatins 15 and related euphane triterpenes from the tree Melia dubia. J. Nat. Prod. 2002, 65, 1886-1891. 
34. Priyadarsini, R.V.; Murugan, R.S.; Sripriya, P.; Karunagaran, D.; Nagini, S. The neem limonoids azadirachtin and nimbolide induce cell cycle arrest and mitochondria-mediated apoptosis in human cervical cancer (HeLa) cells. Free Radical Res. 2010, 44, 624-634

35. Biavatti, M.W.; Vieira, P.C.; da Silva, M.F.G.; Fernandes, J.B.; Albuquerque, S.; Magalhaes, C.M.I.; Pagnocca, F.C. Chemistry and bioactivity of Raulinoa echinata Cowan, an endemis Brazilian Rutaceae species. Phytomedicine 2001, 8, 121-124.

36. Kim, B.; Kim, H.; Choi, J.W.; Lee, C.K. The effects of meliae toosendan fructus on liver function. III. Effects of melianone and 28-deacetyl sendanin on drug metabolism and bile juice secretion. Korean J. Pharmacogn. 1996, 27, 47-52.

37. Ntalli, N.G.; Menkissoglu-Spiroudi, U.; Giannakou, I.O.; Prophetou-Athanasiadou, D.A. Efficacy evaluation of a neem (Azadirachta indica A. Juss) formulation against root-knot nematodes Meloidogyne incognita. Crop Prot. 2009, 28, 489-494.

38. Denizot, F.; Lang, R. Rapid colorimetric assay for cell growth and survival. Modifications to the tetrazolium dye procedure giving improved sensitivity and reliability. J. Immunol. Methods 1986, 89, 271-277.

39. Hussey, R.S.; Barker, K.R. A comparison of methods of collecting inocula of Meloidogyne spp. including a new technique. Plant Dis. Rep. 1973, 57, 1025-1028.

40. Puntener, W. Manual for Field Trials in Plant Protection, 2nd ed.; Ciba Geigy Limited: Basel, Switzerland, 1981; p. 205.

Sample Availability: Samples of the compounds are available from the authors.

(C) 2010 by the authors; licensee MDPI, Basel, Switzerland. This article is an open access article distributed under the terms and conditions of the Creative Commons Attribution license (http://creativecommons.org/licenses/by/3.0/). 